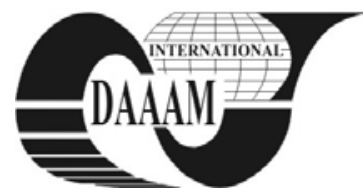

Annals of DAAAM for 2011 \& Proceedings of the 22nd International DAAAM Symposium, Volume 22, No. 1, ISSN $1726-9679$ ISBN 978-3-901509-83-4, Editor B. Katalinic, Published by DAAAM International, Vienna, Austria, EU, 2011 Make Harmony between Technology and Nature, and Your Mind will Fly Free as a Bird

\title{
RESIDUAL STRESS MEASUREMENT BY X-RAY DIFFRACTION METHOD
}

\author{
DUBOVSKA, R[ozmarina]; MAJERIK, J[ozef]; CHOCHLIKOVA, H[enrieta] \& BASKA, I[van]
}

\begin{abstract}
The main aim is to assess the contribution of surface layers of alloy AlZn5Mg2Cu1 by determining the value and type of residual stress under the surface finish. This study is a continuation of the solutions of grant VEGA no. 1/9428/02 titled Technological heredity machined surfaces, high strength materials. The first chapter discussed the possibilities and technological challenges in machining Al-alloys. The second chapter discusses about non-destructive method of measuring residual stress of the first type. In the third and fourth chapter describes a specific experiment method of measuring residual stress by $X$-ray diffraction. This contribution, together with published results is a basis that will enable optimizing the machining process, automotive parts of their dominant functional areas.
\end{abstract}

Key words: $x$-ray diffraction, residual stress, machined surface, Bragg law, Brag-Brentano diffractometer

\section{INTRODUCTION}

The main aim of this paper is to study and analyze technological problems in machining parts from aluminum alloys. Given the fact the constant development of new aluminium alloys are also developing a new cutting materials and tools from them. These technological problems were successively analyzed and experimentally verified on selected sample materials (scientifically according to surface integrity residual stress measurement by the X-ray diffraction method) and also tested in serial production of long-produced parts.

The one of the most important technological challenges in turning aluminum alloys, have generally analyzed in this paper (example of residual stress measurement) includes:

- unsuitable shape of particles emerging in turning especially pure aluminum and soft alloys, turnings and ribbon formation problems in their removal, particularly when working on automated machine tools,

- problems of up edge at the forefront of cutting tool, causing the low cutting speed $\mathrm{v}_{\mathrm{c}}=25 \div 100 \mathrm{~m} \cdot \mathrm{min}^{-1}$, the deterioration of machined surface roughness and the effect of reducing the durability of the tools,

- microgeometry surface finish and its observance throughout the life of the instrument,

- $\quad$ formation and heat for turning the workpiece, which is a good conductor of heat, which influences the dimensional changes of machined parts for the entire series,

- wear of the cutting wedge tool particularly in tooling and eutectic nadeutektických silumin alloy with hard abrasive parts,

- choosing the right type of cutting material according to the types of machining aluminum alloys, the shape, geometry and quality required of surface active tools,

- $\quad$ trembling when machining turning, choosing high cutting speeds in the range of $\mathrm{v}_{\mathrm{c}}=1000 \div 3000 \mathrm{~m} \cdot \mathrm{min}^{-1}$,

- work with dry or cooling process fluids suitable for finishing turning in terms of drawing the desired surface roughness of the product.

\section{RESIDUAL STRESS MEASUREMENT}

To measure the residual stresses are not yet available a simple and sophisticated methods. All methods now used are either cumbersome or difficult, and the equipment and measurement techniques, or are inaccurate. When setting the voltage profile in the direction normal to the surface of these methods lead to damage almost always examined or part of the sample, which further restricts its use. The historical sequence has a residual voltage is measured:

- The macroscopic deformation after removal of the released volume of material in which residual stress acted. This principle forms the basis of all mechanical methods.

- Residual deformation of a metal grid. On this principle, built X-ray and neutron diffraction.

- Various physical quantities affected by stress, for example ultrasonic and magnetic.

Residual stress influences on the machining accuracy and function of parts. Compressive stress ( $\sigma-)$ increases the fatigue strength of components and tensile residual stress $\left(\sigma^{+}\right)$it reduces as much true for high-strength and particularly hardened steel, whose fatigue strength depends on the voltage. The size and distribution of residual stress depends on the degree and depth of surface layer deformation and the ratio $\mathrm{Re} / \mathrm{Rm}$ (Batora \& Vasilko, 2000).

Image processing techniques were applied to assess the inplane strain field. A finite-element code (ANSYS) was used to simulate the stress relaxation process, whose values were compared with the experimental data, and to calculate the holedrilling calibration constants (Ribeiro et al., 2009).

To measure the residual stresses released after a hole drilling a set up able to measure in-plane deformations is normally used, since the most important stress relaxation occurs in plane. Traditionally strain gauges are used to measure strain relaxation, however, optical techniques can measure both in-plane and out-plane displacements. For the assessment of in-plane residual stresses using optical techniques, moiré interferometry and double-illumination are the most used. Image processing algorithms, involving filtering, phase calculation, unwrapping and spatial differentiation are used in data post-processing to transform surface displacement into residual stress fields (Ribeiro et al., 2011)

\section{X-RAY DIFFRACTION METHOD}

The principle of x-ray diffraction consists of homogeneous crystal lattice measurement. The main measuring area is in various oriented directions of each material grain. X-ray beams are measured in definite deep of investigated material and consistently detected surface and subsurface elastic strain from diffraction of x-ray beams (Majerik \& Bajcik, 2009).

The residual stresses in the basics phase of material are composited of two parts. In the first instance may be the difference between stiffness and different orientation of each 
grain and it can be explained or used theoretically or by the research determinated elastic diffraction constants. In the second instance it can be caused by differences in the elasticplastical effect of the next grains.

The principle of this method measurement consists of monochromatic x-ray beam diffraction at the high diffraction angle $2 \theta$ on the surface of material. The measured specimen is revoluted in direction of the angle $\psi$. Angle $\psi$ which defined the rotation of surface specimen is angle between vertical line of surface and diffracted planes of specimen crystal lattice. The diffraction occured by the angle $2 \theta$ defined by the Braggs law. For residual stress of 1 st type by $\mathrm{x}$-ray diffracton determination is possible to get along the changes of stress spacing in the crystal lattice (Withers \& Bhadeshia, 2001).

\section{EXPERIMENTAL MEASUREMENT\&RESULTS}

For measuring residual stresses by X-ray diffraction (see Fig.1) has been prepared CASE samples Ø20H6x28 mm from alloy AlZn5Mg2Cul for surface integrity research. The aim was to determine how technology affects the production of surface CASE to residual surface tension. The samples have been prepared: a) by turning with PCD in the following cutting conditions and cooling: $\mathrm{p}=0.25 \mathrm{~mm}, \mathrm{f}=0.101 \mathrm{~mm}, \mathrm{v}_{\mathrm{c}}=115$ m. $\min ^{-1}, r_{\varepsilon}=0.4 \mathrm{~mm}$, b) by carbide turning with $\mathrm{r}_{\varepsilon}=0.4 \mathrm{~mm}$ at the following cutting conditions: $\mathrm{v}_{\mathrm{c}}=115 \mathrm{~m} \cdot \mathrm{min}^{-1}, \mathrm{p}=0.25$ $\mathrm{mm}, \mathrm{f}=0.141 \mathrm{~mm}$ with a coolant and roller pulley forming at $\mathrm{P}=150 \mathrm{~N}, \mathrm{f}=0.1 \mathrm{~mm}, \mathrm{c}$ ) plunge grinding on the BU-28 machine for the following cutting parameters: $D_{k}=400 \mathrm{~mm}$, width $=30$ $\mathrm{mm}, \mathrm{v}_{\mathrm{gw}}=30 \mathrm{~m} \cdot \mathrm{s}^{-1}, \mathrm{n}_{\mathrm{wpc}}=180 \mathrm{~min}^{-1}, \mathrm{a}_{\mathrm{p}}=0,02 \mathrm{~mm}$, cooling.

It is seen that the maximum residual compressive stress is achieved at the plate with samples turned from solid carbide and then roller. These measured compressive residual stress for all types of samples tested have a positive impact on the operational characteristics of functional surfaces of aluminum alloy components.

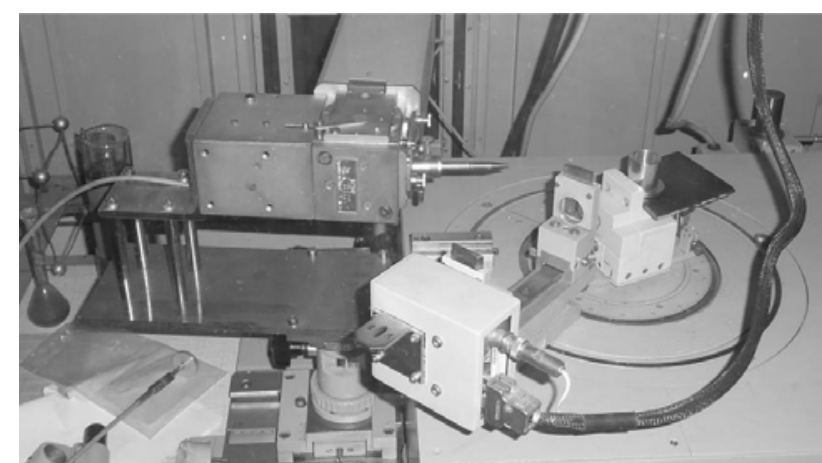

Fig. 1.Residual stress measurement by the $\mathrm{X}$-ray diffraction method using HZG-4 diffractometer in Bragg-Brentano configuration

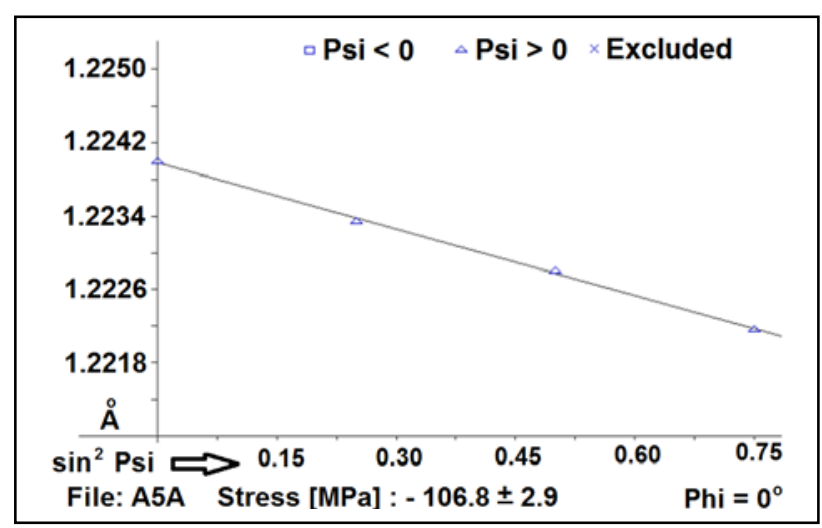

Fig. 2.Measured and processed data A5A samples of Al-alloy: AlZn5Mg2Cu1 turned with PCD cutting tool insert

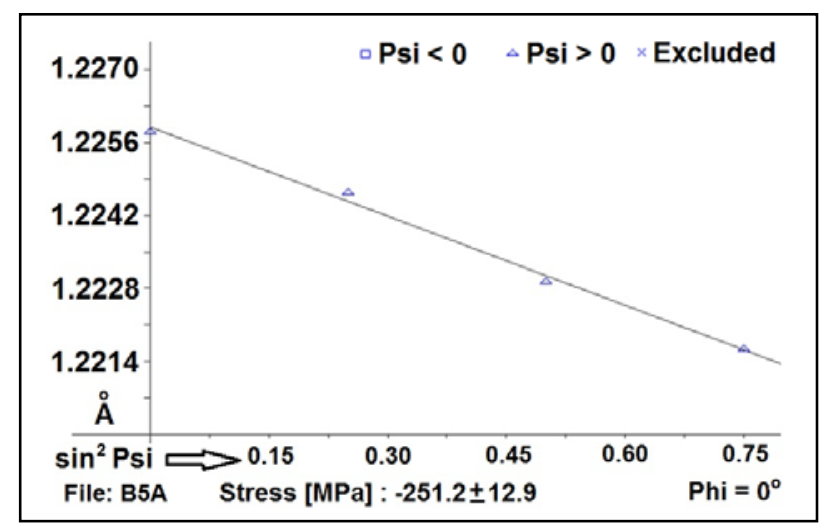

Fig. 3.Measured and processed data B5A samples turned by carbide insert and then by the roller pulley formed

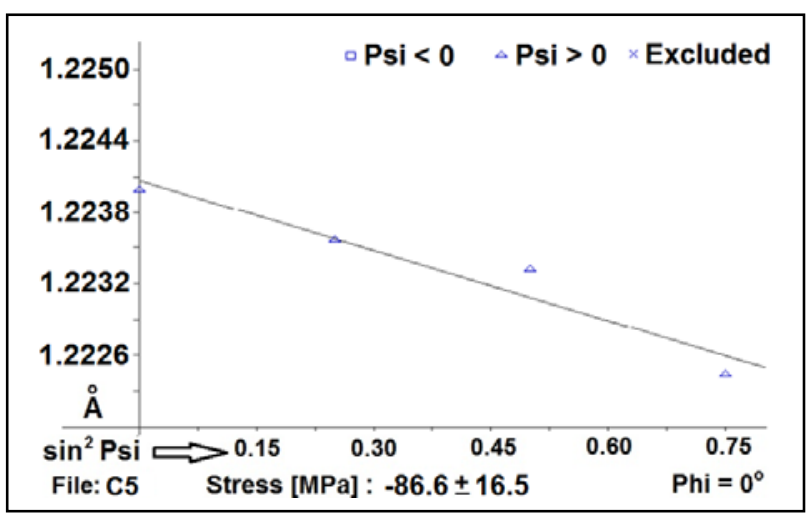

Fig. 4.Measured and processed data C5 samples of alloy: AlZn5Mg2Cu1 after the plunge grinding method.

\section{CONCLUSION}

Measurements of surface residual stress was carried out on samples made of Al-alloys prepared by turning to the polycrystalline diamnod (PCD), turning with the carbides and a roller pressured of $\mathrm{P}=150 \mathrm{~N}$, as well as the way of cut plunge the grinder BU-28, all with a cooler E5\%. The results of the measured values of compressive stress $(\sigma)$ are listed in chapter no. 4 and figures 2, 3, 4. All this can be stated that the aims of measuring residual stress $\mathrm{X}$-ray diffraction have been fully met.

\section{REFERENCES}

Batora, B. \& Vasilko, K. (2000). Obrobene povrchy technologicka dedičnost', funkčnost', FST TnUAD Trencin, ISBN 80-88914-19-1, Trencin, Slovakia

Majerik, J \& Bajcik, S. (2009). Residual Stresses Measurement after High Strength Steels Grinding by High Cutting Speeds Application, Annals of DAAAM for 2009 \& Proceedings of the 20th International DAAAM Symposium, 25-28th November 2009, Austria Center Vienna, ISSN 1726-9679, ISBN 978-3-901509-70-4, Katalinic, B.(Ed.), pp. 18111813, Vienna, Austria

Ribeiro, J. et al. (2009). Measurement of residual stresses with optical techniques. Strain - An International Journal for Experimental Mechanics, Vol.45, No.2, (april 2009) page numbers (123-130), print ISSN 0039-2103

Ribeiro, J. et al. (2011). Moiré Interferometry Assessment of Residual Stress Variation in Depth on a Shot Peened Surface. Strain - An International Journal for Experimental Mechanics, Vol.47, No.3, (june 2011) page numbers (e542e550), online ISSN 1475-1305

Withers, P.J. \& Bhadeshia, H.K.D.H. (2001). Residual Stress Part 1- Measurement Techniques. Materials Science and technology, Vol.17, No.4, (april 2001) page numbers (355365), ISSN 0267-0836 